\title{
NA LAPA TUDO É PERMITIDO! A LAPA SOB O OLHAR E A EXPERIÊNCIA DE TRAVESTIS DAS ANTIGAS ${ }^{1}$
}

Monica S.Siqueira

Doutoranda em Antropologia Social/PPGAS/UFSC

\author{
Ana Luiza Carvalho da Rocha (Orientação)
}

\section{Introdução}

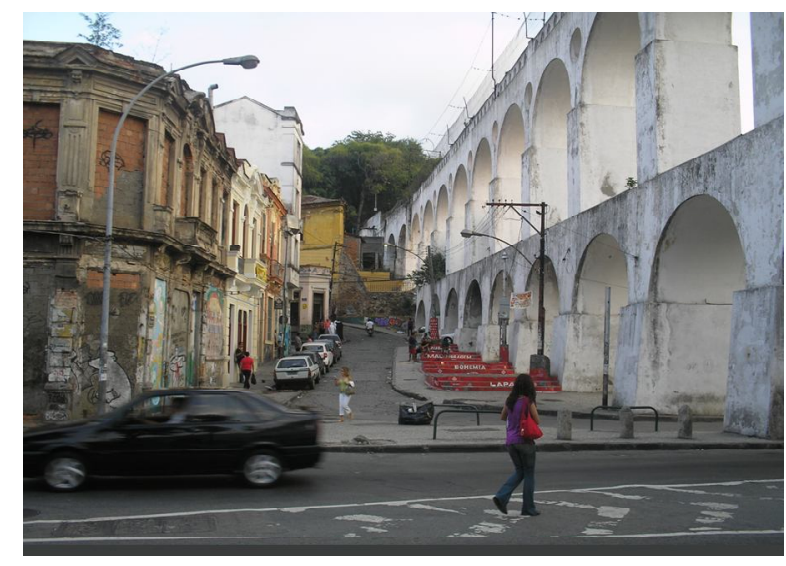

(Lapa, Rio de Janeiro, 2007. Foto da pesquisadora)

"O Viaduto dos Arcos é uma construção sombria e elegante por onde passa, no ar, o bondinho de Santa Teresa, entre muros de arame. Entre os pilares do viaduto estacionam velhos caminhões, guiados por motoristas taciturnos, que esperam cargas ou ordens de serviço. Uma ladeira de empedrado desigual e afiado conduz a primeira, escura, tristonha Rua da Lapa, a Joaquim Silva. Os Arcos estão cinturados por alguns botequins onde se bebe muita cachaça e se comem siris e lingüiça frita. Durante a noite se encontram ali marinheiros e mulheres embriagadas que usam vestidos de veludo colantes e aumentam o tamanho dos lábios com batom. É também o caminho para os cabarés muito mal freqüentados, onde figuras conhecidas do noticiário policial, após um golpe bem sucedido, oferecem champanhas a louras oxigenadas, cada uma com pelo menos um dente de ouro. $O$ bondinho passa como estrépito lá por cima enquanto nos sobrados amarelos e desbotados abrem-se janelas e se debruçam mocinhas de trança, filhas de portugueses proprietários de

\footnotetext{
${ }^{1}$ Durante minha pesquisa de campo para o mestrado realizada em 2003 um dos termos classificatórios utilizados pelas travestis ao se dirigirem as travestis mais velhas era justamente a expressão travestis das antigas que deve ser compreendido muito menos como um termo pejorativo e mais como um termo que procura da conta da experiência de vida e a sobrevivência dessas pessoas no grupo e na sociedade como um todo.
} 
botequins, as quais aspiram de felicidade porque o dia está lindo e o bondinho esta passando. Um homem de roupas sujas e rasgadas, com enormes pés em cuja sola aderiu para sempre uma espécie de visgo, dorme profundamente na calçada. Ao meio-dia o calor ali é intenso: os automóveis levantam poeira de asfalto. Operários obscuros, comerciários, se dirigem as pensõezinhas dos sobrados, onde a refeição comercial consta de arroz, feijão, bife, alface, tomate, goiabada ou marmelada de sobremesa e um cafezinho requentado que já vem com açúcar. As mesas dos refeitórios estão forradas com toalhas de plástico quadriculadas furadas em alguns pontos, e na parede sem dúvida existe um quadro: o Sagrado Coração de Jesus. E assim são os Arcos e suas imediações." (Ramalho, 2007. Crônicas do Rio Antigo).

Neste ensaio trago reflexões de caráter preliminar decorrentes dos primeiros meses de trabalho de campo para fins de doutoramento com um grupo de travestis acima dos 60 anos e residentes na cidade do Rio de Janeiro. Tal investigação tem como proposta principal, compreender os processos pelos quais este grupo foi construindo ao longo de suas trajetórias sociais e por intermédio de seus itinerários urbanos, suas práticas de sociabilidade relacionadas às suas vivências na cidade do Rio de Janeiro. Pensar as práticas de sociabilidades especificas deste grupo nos leva a análise de suas interações sociais e conseqüentemente das formas de apropriação do espaço urbano bem como de suas relações, percepções e concepções da cidade, entendida aqui como cenário de atuação desses atores sociais. Deste modo, para os propósitos deste texto destaco fragmentos de narrativas e vivências de três interlocutoras moradoras ou antigas moradoras do bairro da Lapa e arredores.

O bairro da Lapa ${ }^{2}$ foi fundado em 1751 e se desenvolveu ao redor da Igreja Nossa Senhora do Carmo da Lapa do Desterro no largo e dos Arcos da Carioca o aqueduto concluído em meados do século XVIII durante a administração do Governador-Geral Gomes Freire de Andrade. Esta situada no centro da cidade, e destaca-se como um dos principais símbolos do Rio de Janeiro, por sua notória vida noturna devido aos antigos cabarés e zonas de meretrício (Cosme, 2005) e por seus célebres moradores ou antigos habitués como: Villa Lobos, Lima Barreto, Manuel Bandeira, Di Cavalcanti, Sergio Buarque de Holanda, entre outros artistas, músicos e intelectuais, sem falar nos míticos malandros com seus chapéus Chile, terno de linho branco e sapatos bicos finos, tendo como

\footnotetext{
${ }^{2}$ De acordo com a Prefeitura da Cidade do Rio de Janeiro a Lapa é uma sub-região do Centro da cidade, não sendo, portanto considerado um bairro em si. No entanto, aqui faço referencia ao local como bairro tendo em vista que os próprios moradores - e em geral o próprio imaginário popular carioca - se referem à Lapa como um bairro do Rio de Janeiro.
} 
representante mais famoso Madame Satã considerado como o primeiro "travesti-artista"3 do Rio de Janeiro. Ao longo dos séculos o bairro passou por diversas transformações urbanas e de estilo de vida. Se no inicio se caracterizava por ser um bairro familiar, aristocrático e centro político a partir de 1910 a paisagem do bairro ganha novos aspectos com a instalação das primeiras pensões de mulheres que nos anos seguintes tomaram as ruas e becos do bairro de assalto, um dos mais famosos é o beco das carmelitas onde as casas funcionavam durante todo o dia. Principalmente as décadas de 20 e 30 do século passado foram consideradas pelos ilustres poetas, intelectuais e músicos como a Montmartre ou Montparnasse carioca caracterizando o "Rio Noturno" em alusão aos áureos tempos da boêmia do bairro. (Santos de Lima Costa, 2000)

E apesar de o trecho supracitado estar se referindo a uma Lapa de meados do século $\mathrm{XX}$, guardadas as devidas proporções e temporalidades, também poderia ser uma crônica do bairro bastante atual. Afinal, muitos são os autores ${ }^{4}$ que procuram evidenciar que desde muito cedo a Lapa tem um temperamento que prima pela ambigüidade; abrigando tanto o lócus do "sagrado" através do marco da cidade, a Igreja Nossa Senhora do Carmo, como o lócus do "profano" através dos seus personagens de "caráter duvidoso", os malandros, sambistas, prostitutas, e traficantes. Ao longo dos anos algumas representações do bairro giraram em torno de seu "caráter permissivo", de gestor dos mais transgressores estilos de vida e, portanto ambiente propicio para os tais personagens "misteriosos" e "enigmáticos" citados acima como os malandros e logicamente... As travestis ${ }^{5}$. Aqui intenciono dar ênfase justamente a essas personagens compreendendo-as como uma cronista do bairro onde mora, ou já morou, no intuito de apreender seus pontos de vistas, percepções e vivências.

Portanto, a travesti neste trabalho será compreendida então como um cronistapassante (Lemebel, 1993) que em sua flaneria para nós desconcertante não somente experimenta o seu corpo e a sua sexualidade desprendida da cidade normativa, mas que como uma cronista, uma narradora, em termos de Benjamim, observa e nos conta o que viu e o que vê, uma narração urbana povoada de contradições, desarticulações de uma cidade que transborda no passeio do cronista. Uma cidade que teria como representante a figura da

\footnotetext{
${ }^{3} \mathrm{~A}$ designação travesti-artista refere-se neste caso a alguém que de acordo com seu sexo biológico é considerado masculino e se apresenta em casas noturnas com indumentária e performance femininas.

${ }^{4}$ Refiro-me principalmente aos trabalhos de Santos de Lima Costa (2000), Damatta, Gasparino (1965) e Cosme Elias (2005)

${ }^{5}$ Silva (1993) em sua etnografia sobre as travestis que se prostituíam na Lapa durante o inicio da década de 90 do século passado considera a travesti como transformação social do antigo malandro personagem tão emblemático do bairro em meados deste século.
} 
travesti que em seus itinerários, desarma, ironiza, altera e questiona os espaços urbanos disciplinados, revelando, em seu exercício de subversão de categorias fixas de uma sociedade heteronormativa ${ }^{6}$, as rupturas, fissuras, e rachaduras da urbe ${ }^{7}$.

Ao mesmo tempo, concordamos com Bosi (2006) que o bairro tem para além de sua fisionomia uma biografia que se mistura com as biografias de seus habitantes. Desta forma, em uma das nossas conversas Laura - uma das minhas interlocutoras - me convida para acompanhá-la durante suas caminhadas habituais pelo bairro onde mora há mais de 30 anos, Laura quer demonstrar o quanto ela é apreciada pelas pessoas do seu bairro, quer que eu veja seus itinerários diurnos: padaria, mercado, banca de jornal, a tradicional feira. O convite para essas caminhadas não é em vão e tem sobretudo a intenção de me mostrar seu envolvimento e vivência do bairro que vai além dos espaços e horários normalmente consagrados ao seu "grupo social".

Logicamente que estaremos falando também da própria memória vivida, cotidiana da travestilidade como fenômeno em suas contingências sociais, culturais e históricas. Uma memória que acreditamos compreender criticamente e, portanto criativamente a partir das narrativas e experiências de suas protagonistas.

\section{O que elas nos dizem sobre a Lapa}

"A Lapa era muito boêmia. Dizem hoje que a Lapa esta na moda. A Lapa nunca saiu de moda. Naquela época era muito melhor. Agora você vê muita droga, muita barra pesada, traficante, muitas tribos, entendeu? Gente bunda mole... Não é aquela gente que andava de terno, bem vestido, bonito. Para entrar numa boate, para conquistar uma prostituta, tinha muitas prostitutas nos cabarés. E a gente também fazia muito cabaré junto

\footnotetext{
${ }^{6}$ Butler argumenta que "os travestis subvertem inteiramente a distinção entre os espaços psíquicos internos e externos, e zombam efetivamente do modelo expressivo do gênero e da idéia de uma verdadeira identidade de gênero". Ao construírem um corpo feminino e masculino visto como ambíguo, travestis, transexuais, transformistas, drags também indicam ações que contrastam o gênero como dual e essencializado, para afirmá-lo múltiplo, inacabado, enfim performático. Assim esses sujeitos nos colocam diante o caráter artificial do gênero pondo em xeque e transcendendo o sistema de gênero binário pelo qual se pauta a sociedade ocidental tida para autora como heteronormativa. Sujeitos que são considerados um espaço de possibilidade discursivas, um modo de rearticular e desnaturalizar concepções fixas de conhecimento.

${ }^{7}$ Neste sentido, acredito ser pertinente retomar a De Certeau em suas reflexões sobre a cidade e as práticas urbanas colocam que a vida urbana deixa sempre mais remontar aquilo que o projeto urbanístico dela excluía. A linguagem do poder se urbaniza, mas a cidade se vê entregue a movimentos contraditórios que se compensam e se combinam fora do poder panóptico. Sob os discursos que a ideologizam, proliferam as astúcias e as combinações de poderes sem identidade, legível, sem tomadas apreensíveis, sem transparência racional impossíveis de gerir. (De Certeau, 1997).
} 
com as prostitutas. Éramos atrações, eu não era tanto porque era menor. Mas eu via as travestis.Era diferente, era uma Lapa maravilhosa”. (Janete, 60 anos, cabelereira e cantora)

"A Lapa agora é um point, as pessoas vão pra lá. Tem o circo voador, a Fundição Progresso, tem uma ruazinha a Joaquim Silva fica repleta de gente. Parece até o pelourinho, cheio de gente, de barraca. Diz que rola muita droga. É um fervo danado. Lapa tem de tudo. Até gente de Copacabana vai para Lapa. Fica supercongestionada. Gente passando pra lá e pra cá. Gente bonita, gringos, eu mesmo quando ia para Lapa ficava sentada lá para apreciar a gente passando, gente passando bonita, chiquérrima. Muito diferente da minha época. Melhorou bastante, não tem mais aquela malandragem, os travestis roubando, era correria para cá, correria pra lá. As bichas roubando os clientes. Agora acabou isso. Uma freqüência de gente fina. Aquelas casas finas, cada dia inaugura uma nova. A Lapa ficou fina, a freqüencia de gente de classe média para cima. Na minha época era só marginal, travesti, gente matava ali, policia prendendo os travestis."

"Em 70 o bom era a Cinelândia, as famílias iam ao cinema. Hoje em dia é muito perigoso. Naquela época não tínhamos medo de ficar na rua à noite. Eu ficava na Lapa até as 5hs. A Lapa não enchia tanto como agora. Os travestis ficavam mais na Lapa. Embaixo dos Arcos, no Casanova, na Men de Sá. Não ficava na Augusto Severo. Ficavam no Beco das Carmelitas. Era muito bom, vinha travestis da América do Sul, para colocarem silicone. Aqui era como fosse uma Europa hoje. As travestis belíssimas, produzidas, todas com roupas finas, não ficavam peladas não, com scarpin, meias arrastões, superprodução, a que ganhava mais era que tinha mais produção.

Hoje acabou. Inaugurou aqueles bares todos, antigamente ficava cheio a Men de Sá, a Lavradio. Do outro lado, no bar Sete Portas, a gente ficava no posto de gasolina ali, a Lapa era enfestada, rodeava ali tudo, do Casanova até Gomes Freire era rodeada de Travestis, na Rua do Resende esquina com Gomes Freire, no Hotel Peon ficavam as mais belas. Agora fica só um pedacinho na porta do Hotel Novo Mundo, uma mixaria em vista do que era antigamente, agora acabou a prostituição na Lapa, esta mais na Augusto, tem algumas estão tentando relançar e voltaram fazer ponto na rua do Resende. A Lapa é muito cheia, os clientes tem vergonha de sair, a Lapa deixou de ser um ponto para travetis" (Raquel, 67 anos aposentada)

"A Lapa na década de 60 não era como hoje em dia um ponto turístico. Underground era meio escura, hospedarias, a pegação era melhor, com esse tumulto de gente atrapalha muito. A pessoa que ia para Lapa tinha objetivo, era ponto auge para pegação, não tinham especificamente boates gays, tinha um bar na Marechal Floriano chamado Barítono. Ponto de encontro entre marinheiros e veados, lá tinha uma vitrolinha que a gente colocava música e ali se apaixonava e ia para hospedaria. Hoje as pessoas vão para apresentar seus tipos".

(Laura, 67anos, artista e professora aposentada) 
Sendo nos últimos anos uma personagem muito popular no bairro, Laura se autodefine como uma "figura da Lapa", destacando seu pertencimento simbólico ao local. Uma vez, maquiada e vestida para um dos seus shows, sentada em um banco de cimento na calçada de uma das suas ruas mais movimentadas, comenta comigo: aqui na Lapa não tem problema, ninguém olha para ninguém! A principio, é possível perceber através dos relatos algumas representações da Lapa bastante recorrentes, que podemos encontrar em muitas das reportagens, livros e crônicas sobre o bairro. Destacar o bairro como boêmio, berço da malandragem, local de convivência de diversos grupos sociais onde as diferenças sociais, culturais e de classes são suavizadas, já se tornou lugar comum. Por outro lado, podemos perceber olhares diferenciados destas características do bairro que estão intrinsecamente relacionados com as experiências e trajetórias de vida dessas personagens.

Nenhuma de nossas personagens nasceu no bairro ou em seus arredores, morar na Lapa ou em suas áreas limítrofes, mas que por vezes se confunde com ele, representou mudanças significativas em suas vidas. Uma ruptura com um estilo de vida mais familiar, a saída da casa dos pais, certo afastamento da comunidade de origem. Advindas de bairros da Zona Norte da cidade fixar residência na Lapa, em um primeiro momento, em hospedarias baratas ou em pequenos apartamentos do tipo quarto e sala muito comuns no centro da cidade representou para essas pessoas, acima de tudo, a conquista da liberdade sexual, de vivenciar sua sexualidade e identidade longe dos olhares críticos e controladores dos pais, familiares e vizinhos. Não seriam mais necessários os deslocamentos ocasionais e carregados de mistérios para encontrar amigos e ou parceiros sexuais e principalmente camuflar o self diante de familiares, amigos e vizinhos.

Laura uma vez me confidenciou que saia de casa vestida de boyzinho ${ }^{8}$ e quando chegava à Cinelândia trocava de roupa e de gestual ao lado de uma banca de jornal de um amigo localizada nos arredores. Parker (2002) em seus trabalhos observou um movimento migratório sexual entre pequenas e grandes cidades ou entre bairros de uma mesma cidade. $\mathrm{E}$ destaca o papel inegável da sexualidade, como um fator dentro da equação migratória num grau bem mais expressivo do que tem sido percebido entre homens que fazem sexo com outros homens em lugares como o Brasil contemporâneo (Parker, 2002). É necessário ressaltar que esses deslocamentos, visam além da busca da realização de seus desejos e de

\footnotetext{
${ }^{8}$ É muito comum entre elas usar este termo para dar conta de uma performance heterossexual.
} 
pares sexuais a participação em redes de sociabilidade que em seus bairros de origem não seria possível. Neste sentido, duas idéias são norteadoras de suas representações e experiências sobre e no bairro: as de tolerância e liberdade.

Para uma melhor compreensão de seus pontos de vistas é necessário esclarecer que estamos diante de travestis com trajetórias de vida bem singulares. Silva, em sua célebre etnografia sobre travestis que se prostituem na Lapa em idos dos anos 90 do século XX observou a complexidade e heterogeneidade desse universo, que é composto por travestis, transformistas, transexuais e artistas; um universo de seres que têm como característica principal a ambigüidade. (Silva, 1993). Dentro do grupo elas utilizam de classificações para se distinguirem entre si, e aqui neste trabalho estamos tratando com diferentes perfis. Travestis que recebem a categoria de travestis das antigas ou da velha guarda e que em sua maioria se estabeleceram como artistas no cenário cultural da cidade. São formas diferenciadas de se perceberem entre si, que estabelecem nítidas fronteiras entre elas.

Portanto no que se refere à Janete, por exemplo, que segundo suas informações sempre trabalhou como cabeleireira e artista de Teatro de Revista ${ }^{9}$ suas narrativas estão recheadas de histórias de shows, espetáculos de teatro; enquanto Raquel que concomitante a seu trabalho com escrituraria no Ministério do Trabalho batalhava $^{10}$ nas ruas do bairro à noite, nos fala de sucessivas brigas e assassinatos entre travestis por pontos de batalha ou simplesmente por motivos de ordem passional, ciúmes de namorados, parceiros sexuais e assim por diante. Suas narrativas de memórias estão recheadas de episódios de assaltos, roubos e prisões. É interessante perceber como as diferentes vivências do local de moradia e trabalho pode traçar caminhos que ora nos levam ao luxo, glamour e diversão e ora pode nos levar a episódios considerados violentos e dolorosos. Por outro lado se faz necessário pontuar que estes caminhos também podem se entrecruzar em determinados momentos.

Assim, não é que a Janete não tenha também experienciado esta Lapa digamos menos glamourosa, mas é que nos jogos da memória ao recordar nos apresenta justamente uma Lapa glamourosa, destacando principalmente seu pertencimento há um determinado grupo de travestis, travestis artistas, ou a "travesti arte" como alguma delas costumam demarcar.

O tom de melancolia e de saudosismo que transparece nos relatos da Janete com relação a uma época maravilhosa do bairro em contraste com a atualidade articula-se a um

\footnotetext{
${ }^{9}$ Que teve surgimento no Brasil durante a década de 30 do século passado primeiro com vedetes depois com travestis, espetáculos que mesclavam esquetes cômicos com temas do cotidiano com música e dança que nos fins da década de 60 a 80 teve em teatros da zona sul e do centro da cidade seu auge

${ }^{10}$ Termo êmico utilizado para nomear a prática da prostituição principalmente a realizada na rua.
} 
processo de decadência do próprio ambiente artístico em meados do século XX contexto também do processo de transformação em travesti. Nas últimas décadas, muitos dos cabarés e teatros locais em que atuou fecharam suas portas ou simplesmente não escaparam as demolições ocorridas no bairro e seus arredores. Ao mesmo tempo, os espetáculos de Teatro de Revista não existem mais; exibindo em suas produções travestis que encantavam pela beleza, pelo glamour e pelo talento artístico.

E o processo de banalização do fenômeno só contribui segundo algumas interlocutoras para a própria deterioração do grupo. O sentimento de saudosismo com relação a um determinado estilo de vida do bairro reflete o saudosismo em torno do próprio estilo de travestilidade ${ }^{11}$ ou de travestis que apesar dos percalços de uma sociedade coercitiva eram envoltas por áurea de misticismo e encantamento. Época em que as travestis eram destacadas pelo luxo, glamour e elegância, e que inclusive o país era visto como destino de travestis de outros países da América do Sul, como a Argentina, por exemplo ${ }^{12}$.

Ainda entre as décadas de 50 e 70, as travestis no Rio de Janeiro sofriam severas retaliações se saíssem às ruas, principalmente da parte do poder público, que através de seu aparelho coercitivo policial, restringia e tentava regular não somente as atividades de trottoir do grupo, mas também qualquer espécie de "aparição" desses sujeitos no cenário social. Uma fala da Raquel nos ilustra muito bem este tipo de atuação da policia:

"Ficava na porta do Casanova quando a policia vinha, à gente tinha correr lá para dentro senão a policia pegava". "Tinha um lago ali na Lapa, em frente aos Arcos era uma praça e tinha um lago, às vezes os PMS pegava os travestis e jogava dentro do lago. Eles eram horríveis. A policia perturbava muito."

\footnotetext{
${ }^{11} \mathrm{O}$ termo travestilidades visa, ao mesmo tempo afirmar a positividade das identidades travestis em lugar de.travestismo e sobretudo garantir a pluralidade que permeia o universo das travestis.

${ }^{12}$ Durante o trabalho de campo tive a oportunidade de conhecer uma travesti Argentina de aproximadamente 70 anos que veio para o Brasil no período que iniciou a ditadura em seu país. Tornamo-nos próximas, mas Lu não se sentia bem emocionalmente para participar da pesquisa diretamente. Na época, vivia sozinha em um pequeno quarto alugado na região suburbana da cidade, sempre que nos encontrávamos estava às voltas com uma viajem a Buenos Aires em busca de seus direitos de aposentadoria. No entanto, a longa ausência de contato com os familiares argentinos e o medo do que poderia encontrar lá a faziam sempre recuar.
} 


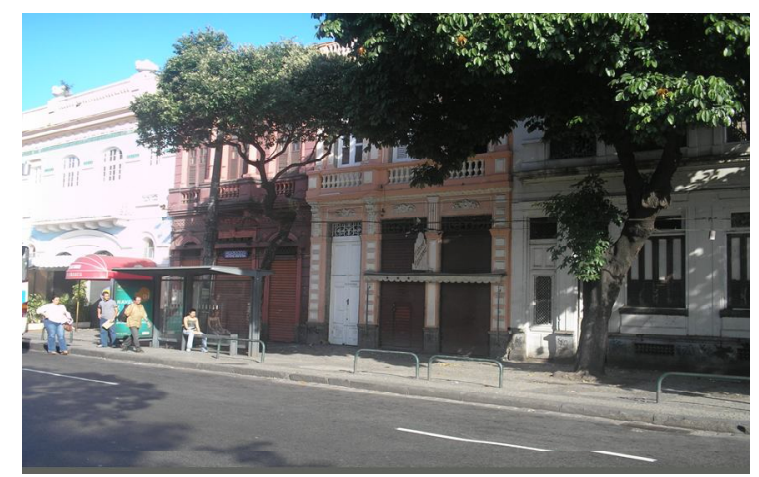

Foto da frente do cabaré CasaNova (sobrado em tom pastel ao centro ) Rua Men de Sá, Lapa RJ. (Foto da pesquisadora)

Encontramos também em suas falas referencias há um momento de decadência do bairro através do estado de abandono dos prédios, dos casarios antigos, as ruas sujas e esburacadas, a falta de iluminação que apesar de dar um aspecto sombrio ao local, por outro lado, em muito possibilitou que nossas personagens fizessem de alguns cantos e esquinas escuras local para a prática do ato sexual. Afinal a própria Laura faz questão de frisar que antes da Lapa passar por todo este processo de revitalização que trouxe novos bares, casas de show, e um fluxo intenso de pessoas durante toda a noite, a pegação ${ }^{13}$ era muito melhor!.

Um aspecto importante para ser destacado é que junto a este processo de revitalização e modernização que vem atravessando o bairro objetivando com a reforma de prédios e casarios antigos e abertura de bares e casas noturnas mais modernas que valorizem a vocação boêmia e musical do bairro imprimir uma cara nova ao local; uma cara nova que gradativamente vem, segundo elas, expulsando as travestis do bairro, principalmente as que praticam a prostituição. Processo tão bem salientado pela Raquel em seu relato e que pode ser facilmente percebido por quem vai a Lapa à noite nos dias atuais. Raquel chama atenção para um período de intensa ocupação do bairro pelas travestis. Temos um movimento de procura de re-ocupar espaços do passado, determinadas ruas afastadas e escuras e principalmente longe dos holofotes da Lapa em sua roupagem moderna.

No final da década de 60 e inicio da década 70 que autores como Green (2002) e Silva $(1993,1996)$ observam a intensa proliferação de travestis no cenário urbano carioca. Esses autores, não estão se referindo apenas em sua presença nos bailes, mas principalmente destaca seu surgimento expressivo nas ruas da cidade e de sua invasão nos bairros do centro

\footnotetext{
${ }^{13}$ Pegação é um termo êmico e pode ser entendido como o momento no qual se estabelece uma relação sexual completa ou apenas envolve ações como beijar na boca, felação, troca de caricias.
} 
e da zona sul, como Copacabana principalmente. Silva (1993) ressalta que o bairro da Lapa foi pioneiro de um fenômeno extremamente curioso que se processou pelos fins da década de 60 e inicio dos anos 70, que foi a progressiva e violenta expulsão das prostitutas femininas pelos travestis que passam a ocupar o bairro, dando cabo a um predomínio de sete décadas.

É interessante que a imagem do bairro que é veiculada pelos guias turísticos, por exemplo, procura enfatizar as características boêmias, o ecletismo de alternativas para lazer e diversão noturna sem deixar, por exemplo, de fazer conexões entre a sujeira, a deterioração do local com as travestis. Como é possível verificar neste trecho:

"Hoje, como cantou Chico Buarque aquela tal malandragem não existe mais, mas o samba e a boêmia seguem mais vivos do que nunca em bares abertos até de madrugada. Deixada de lado por décadas, a Lapa ainda exibe sinais do período de descaso: calçadas sujas, travestis pelas ruas, casarões caindo aos pedaços. Mas imóveis que já foram restaurados e a freqüência de muita jovem que procura diversão sem confusão. Os novos ares trouxeram de volta o circo voador, e a Fundição progresso que promove shows de música eletrônica, hip-hop, reggae e MPB”.

Parafraseando Mayol, o bairro entendido como um pedaço da cidade que é atravessado por um limite distinguindo o espaço privado do público, delimitando fronteiras sociais: é o que resulta de uma caminhada. Em face de uma configuração dos lugares impostos pelo urbanismo, diante dos desníveis sociais internos ao espaço urbano, o usuário sempre consegue criar para si algum lugar de aconchego, itinerários que são as marcas que ele soube, por si mesmo impor ao espaço urbano. (Mayol, 1996). Ao mesmo tempo, concordamos com Bosi (2003) quando declara que há nos habitantes de um bairro o sentimento de pertencerem a uma espécie de tradição, a uma maneira de ser que anima a vida das ruas e das praças, das esquinas, ou seja, a paisagem do bairro tem uma história conquistada numa longa adaptação. Bem, as praças e as esquinas do bairro em questão as nossas personagens conhecem muito bem e à medida que conquistavam o direito de caminhar pelos seus diferentes espaços e experienciar distintas formas de sociabilidade elas conquistavam outros lugares. 


\section{Sociabilidades, entre ontem e hoje? Apontamentos finais}

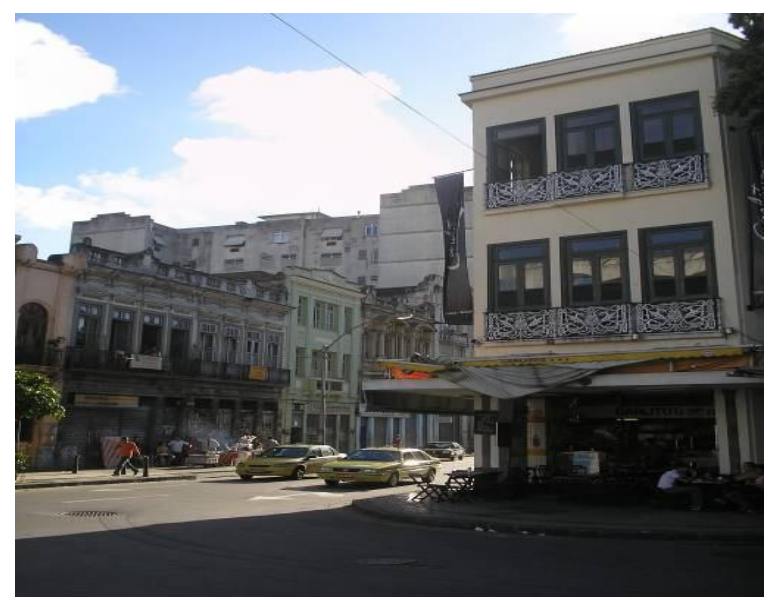

(Esquinas da Men de Sá com Riachuelo, Lapa, RJ, 2007)

Ao trazer à tona algumas representações das travestis acerca de uma localidade da cidade do Rio de Janeiro que em algum momento da trajetória de vida dessas pessoas foi local de moradia e trabalho, sendo que em alguns casos ainda hoje cumpre também este papel acreditamos poder dar conta também de compreender suas experiências nesta cidade ao longo de suas trajetórias sociais e por intermédio de seus itinerários urbanos, visando em um sentido mais amplo, suas formas e praticas de sociabilidade ao longo de suas vidas. Para isso nos detemos nas narrativas de suas memórias articuladas as suas vivências cotidianas na urbe.

A fotografia acima foi tirada por mim durante trabalho de campo em junho de 2007. Era um sábado a tarde de um dia ensolarado, um tipico dia de calor abafado no Rio de Janeiro em que Raquel e eu decidimos ir à praia do Flamengo. A ideia inicial era aproveitar o dia de calor e conhecer o local que, durante algum tempo de sua vida costumava frequentar. A praia do flamengo está localizada no Parque do Flamengo mais conhecido em termos populares como o Aterro do Flamengo que se prolonga desde o centro da cidade até a praia de Botafogo bairro localizado na zona sul da cidade. É um dos locais mais tradicionais para o exercicio da sociabilidade homoerótica ${ }^{14}$ sendo destacado com muita frequencia nas

\footnotetext{
${ }^{14}$ Autores como Parker(2002), Green (2002) entre outros também destacaram esta região como um cenário deste tipo de sociabilidade.
} 
narrativas das interlocutoras desta pesquisa. Sempre aparece como um modo de sociabilidade que num primeiro momento estou chamando de evocativas presente apenas em suas lembranças de costumes, hábitos e práticas que já não fazem mais parte de suas vidas no cotidiano.

Deste modo, assim que chegamoos ao local Raquel percebeu que não poderiamos ter acesso ao "pedaço da praia" que costumava a frequentar pois estava fechado por um muro feito de madeira que cercava toda a região. O local em questão não fica exatamente na praia estaria localizado em seus arredores, já na parte gramada do aterro. Como uma boa parte do aterro estava em obras o acesso a população estava proibido. Vencida nossa frustração resolvemos encontrar um local para aproveitarmos o sol ali mesmo na areia da praia. Durante aproximadamente as duas horas que permanecemos na praia muitos foram os temas de nossas conversas: as pessoas que frequentam a praia, os cuidados que deveriamos ter com os nossos objetos já que é comum ocorrerem pequenos furtos, algumas observações e estórias sobre a época em que frequentava a praia com assiduidade normalmente junto com alguma amiga também travesti. Há dois anos que Raquel não ia a praia e se em parte foi decepcionante não poder estar no local de costume parece que apreciou a oportunidade de “estar em outro lugar" desta vez.

Quando caminhávamos de volta para sua casa, e ao atravessarmos os arcos da Lapa esta me aponta justamente o bar que podemos ver na foto e exclama num tom nostálgico: "Aqui onde tem este bar tinha uma oficina e um outro bar que vendia comida e que eu frequentava toda noite depois da batalha. Era muito bom".

$\mathrm{O}$ bar ficava aberto durante toda a noite até o amanhacer e era frequentado durante a madrugada pelas travestis que faziam pista na Lapa ou mesmo moravam no bairro. De acordo com Raquel, ficava localizado bem na calçada de uma antiga oficina mecânica e borracharia, onde o proprietario colocava um grande isopor com refrigerantes, cerveja e água. Uma mesa feita com um tabuleiro, exibia bolos, sanduiches e salgadinhos, um fogão pequeno para as refeições e mesas e cadeiras espalhadas pela calçada formavam a configuração fisica do bar. Por outro lado, muito mais que um lugar para comer após o trabalho, o bar de Dona E era fundamentalmente um ponto de encontro e do exercicio da sociabilidade entre elas, apesar de ser voltado mais especificamente para as travestis que se prostituiam na rua, o local também servia de ponto de encontro para taxistas e eventuais 
clientes.. Um local onde compartilhavam experiências relacionadas ao trabalho, romances, questões familiares, problemas financeiros.

As recordações de Raquel sobre o local são envoltas em muito afeto e alegria. Ali encontrava seus pares, suas amigas, eventualmente podia estar com alguns de seus inúmeros maridos simplesmente para um bate e papo. Não que o local não fosse palco de situações de conflitos. Afinal o conflito ou melhor as situações de conflito são parte constitutivas das relações estabelecidas entre elas. Durante o campo por inúmeras vezes pude constatar e presenciar discussões e brigas às vezes extremamente passageiras outras nem tanto que perduravam algumas semanas e serviam de alimento para formentar fofocas e intrigas. No entanto, as brigas, as intrigas são elementos que configuram as relações entre elas e ao mesmo tempo, que podem criar inimizades vão estabelecendo alianças, tanto uma quanto outra podem ou não permanecer ao longo do tempo dependendo do nivel que haja alcançado a discussão ou da "força da aliança". Uma das reinvidações entre algumas interlocutoras da pesquisa era justamente a ausência de um lugar para elas, um local onde pudessem se encontrar e se reunir como no passado, isto é, um espaço onde as relações e interações entre elas se estruturem e que a meu ver implicaria numa fidelidade ao grupo social do qual fazem parte.

Em termos gerais o que podemos observar é que alguns dos locais como a Lapa e o Centro da cidade foram fundamentais no que diz respeito à sociabilidade dessas pessoas, a criação e consolidação de formas de sociabilidade. Cada um desses lugares pode representar formas diversas de sociabilidade; o cinema mais voltado para a busca dos parceiros sexuais, as praças como ponto de encontro entre amigos, voltada para o lazer talvez mais lúdico, mas que por sua vez não impedia o exercicio da paquera. Os teatros, espaços para as que trabalham no ramo artístico, dos grandes momentos de glamour, da realização pessoal, da plenitude da performance feminina. Mas ao mesmo tempo que esses lugares nos colocacam diante de formas e práticas diversas de sociabilidades entre elas nos interpelam também com estilos de travestilidades e portanto com as proprias estratégias de convivencia e manutenção do grupo.

Deste modo, o que vemos até o momento é que a cidade, as diferentes apropriações do espaço urbano, se apresentam para nós como um dos principais quadros de referência das memórias dessas pessoas. Lugares recheados de significados a nível individual e coletivo Cenários para a criação de formas de sociabilidades em alguns casos consideradas marginais, 
e talvez mais do que isso, cenários de "subjetividades marginais". Compreender como determinados lugares foram se constituindo como espaços de sociabilidade e apresentar estes lugares é mostrar como esses sujeitos foram desenvolvendo vínculos com a cidade e se constituindo como cidadãs. Enfim é como nos diz Eckert e Rocha (2000):

"a memória desempenha um papel essencial na compreensão das lógicas de apropriação dos espaços urbanos na contemporaneidade, na medida em que ela organiza o cotidiano e arranja o tempo, tornando-o continuo algo que em si mesmo é fragmentado e descontinuo marcado por cortes e rupturas. A memória que os grupos urbanos detêm acerca dos seus territórios de vida é então, como que uma luta contra a ação corrosiva do tempo nas modernas sociedades contemporâneas, já que é a memória que mantém vivo os espaços imaginados e os espaços anteriormente vividos pelos habitantes dos grandes centros urbanos é ela que orienta a nossa vivência cotidiana e a própria vida da cidade”.

\section{REFERÊNCIAS}

ALVES, Andréa. A dama e o cavalheiro: um estudo antropológico sobre envelhecimento, gênero e sociabilidade. Rio de Janeiro: Editora FGV, 2004

ÁRIES, Philipe e BÉJIN, André (orgs.). Sexualidades ocidentais. São Paulo: Ed. Brasiliense, 1986.

BARROS, Myriam Lins de. "Testemunho de vida: um estudo antropológico de mulheres na velhice”. Perspectivas antropológicas da mulher. Rio de Janeiro: Zahar, 1981.

------- (org.) Velhice ou Terceira Idade. Estudos antropológicos sobre identidade, memória e política. Rio de Janeiro: Editora FGV, 2000.

---- "Rede sociais e cotidiano de velhos num subúrbio carioca". Interseções: Revista de Estudos Interdisciplinares. PPCIS-UERJ, ano 3, n.2, 2001.

----- " O passado no Presente. Aos 70 falando do Rio de Janeiro". A cidade em imagens. Cadernos de Antropologia e Imagem. UERJ, ano 3, n. 4, 1997.

BENJAMIN. Walter. O Narrador: considerações sobre a obra de Nikolai Leskov. In: Obras escolhidas. Magia e técnica, arte e política. v.1. São Paulo: Brasiliense, 1990.

BENEDETTI, Marcos Renato. Toda feita: o corpo e o gênero das travestis. Rio de Janeiro: Garamond, 2005.

------ "A calçada das máscaras". In: GOLIN, Célio e WEILER, Luis (orgs.) Homossexualidades, cultura e política. Porto Alegre: Sulina, 2002.

BOSI, Ecléa. Memória e sociedade: lembrança de velhos. São Paulo: Companhia das Letras, 1994.

------- O Tempo vivo da memória - ensaios de psicologia social. São Paulo: Ateliê Editorial, 2003.

BRITO DA MOTTA, Alda. "Chegando pra idade". Revista Estudos Feministas, v. 5, n” 1, Florianópolis: Editora da UFSC, 1997.

------ "Sociabilidades possíveis: idosos e tempo geracional". In: PEIXOTO, Ehlers Clarice.(org.) Família e Envelhecimento. Rio de Janeiro: Editora FGV, 2004.

BUTLER, Judith. Problemas de gênero: feminismo e subversão da identidade. Rio de Janeiro: Civilização Brasileira, 2003. 
-----“'Corpos que pesam: sobre os limites discursivos do sexo”. In: LOURO, Guacira Lopes (org.). O corpo educado: pedagogias da sexualidade. Belo Horizonte: Autêntica, 2001.

CABRAL, Benedita E. S. Lima."A vida começa todo dia". In: Revista Estudos Feministas. v 5, no 1. Florianópolis: Editora da UFSC, 1997.

-----"A sociabilidade, alternativa de solidariedade na velhice" In: REUNIÃO DA ASSOCIAÇÃO BRASILEIRA DE ANTROPOLOGIA, 20, 1998, Vitória. Anais .... Vitória, 1998.

CAVENACCI, Máximo. A cidade Polifônica. Ensaio sobre antropologia da comunicação urbana; tradução Cecília Prada- 2ed. São Paulo: Studio Nobel, 1997.

CERTEAU, de Michel. A invenção do cotidiano:1. artes de fazer. Tradução de Ephraim Ferreira Alves.- Petrópolis, RJ: Vozes, 1994.

CEBALLOS, Rodrigo." Trilhas urbanas, armadilhas humanas. A construção de territórios de prazer e de dor na vivência da homossexualidade masculina no Nordeste brasileiro dos anos 1970 e 1980".In: RAISSA SCHPUN, Monica (org). Masculinidades. São Paulo: Boitempo Editorial: Santa Cruz do Sul, Edunisc, 2004.

CLIFFORD, James. A Experiência Etnográfica: antropologia e literatura no século XX. Rio de Janeiro: UFRJ, 1998.

COSTA, Icléia T.M e ORRICO, Evelyn (orgs) Memória, Cultura e Sociedade. Rio de Janeiro: 7 letras, 2002.

CUNHA CAMPOS, Maria Consuelo. "Roberta Close e M. Butterfly: transgênero, testemunho e ficção". In: Revista de Estudos Feministas. v. 7, n. 1 e 2. Florianópolis, 1999.

DAMATTA, Gasparino. Antologia da Lapa: vida boêmia no Rio de Ontem .RJ: Leitura, 1965.

DEBERT, G. "Envelhecimento e representações sobre a velhice" Anais do VI Encontro Nacional de Estudos Populacionais. Caxambu, 1988.

--- "Gênero e envelhecimento". In: Revista Estudos Feministas.v.2, no.3. Florianópolis, 1994.

----"Envelhecimento e curso de vida". In: Revista Estudos Feministas. v. 5, no. 1. Florianópolis, 1997.

-----A reinvenção da velhice: socialização e processos de reprivatização do envelhecimento. São Paulo: EDUSP/FAPESP, 2002.

----- "A antropologia e o estudo dos grupos e das categorias de idade". In: BARROS, Myriam M. Lins de (org.) Velhice ou Terceira Idade. Estudos antropológicos sobre identidade, memória e política, Rio de Janeiro: Editora FGV, 2000a.

---- "Terceira Idade e Solidariedade entre gerações". In: DEBERT, G e Goldstein, D. M. (orgs.) Políticas do corpo e o curso da vida. São Paulo: Editora Sumaré, 2000b.

ECKERT, Cornélia. "A saudade em festa e a ética da lembrança". In: Revista Estudos Feministas. v. 5, no 1. Florianópolis, 1997.

-----. "Tempo e Memória. Da Duração continua a Dialética da Duração". In: DEBERT, G e Goldstein, D. M. (orgs.) Políticas do corpo e o curso da vida. São Paulo: Editora Sumaré, 2000.

ECKERT, Cornélia e ROCHA, Ana Luiza Carvalho da. O Tempo e a Cidade. Porto Alegre: Editora da UFRGS, 2005.

ERDMANN, Regina Maria. Reis e rainhas no Desterro: um estudo de caso. Dissertação de Mestrado apresentada ao Programa de Pós-Graduação em Ciências Sociais da Universidade Federal de Santa Catarina, 1981.

FLORENTINO, Cristina de Oliveira. Bicha tu tens na barriga, eu sou mulher! - uma etnografia de travestis em P. Alegre. Dissertação de Mestrado apresentada ao programa de 
Pós-Graduação em Antropologia Social da Universidade Federal de Santa Catarina/PPGAS/UFSC, 1998.

FOUCAULT, Michel. História da Sexualidade I: A vontade de Saber. Rio de Janeiro: Graal, 1997.

GREEN, James N. Além do carnaval: a homossexualidade masculina no Brasil do século XX. São Paulo: Ed. Unesp, 2002.

HALL, Stuart. Identidades culturais na pós-modernidade. Rio de Janeiro: DP \& Aed, 2002.

HALBAWACHS, M. A memória coletiva. São Paulo: Vértice, 1992.

HERDT, Gilbert. "Introduction: third sexes and third genders". In: Third sex, third Gender: beyond sexual dimorphism in culture and history. New York: Zone Books, 1996.

JAYME, Juliana Gonzaga. "Montar-se: discutindo corpo e encorporação entre os transgêneros". Trabalho apresentado no GT "Sentidos do Gênero", na IV Reunião de Antropologia do Mercosul. Mimeo.2001a

----- Travestis, transformistas, drag-queens, transexuais: personagens e máscaras no cotidiano de Belo Horizonte e Lisboa. Tese de Doutorado apresentada ao Programa de PósGraduação em Ciências Sociais da UNICAMP, 2001b.

JARDIM, Denise Fagundes. "Performances, reprodução e produção dos corpos masculinos". In: LEAL, Ondina Fachel (org.). Corpo e significado: ensaios de Antropologia Social. Porto Alegre: Ed. da UFRGS, 1995.

LANG, Sabine. There is more than just women and men - gender variance in North American indian cultures. London: Cambridge University Press, 2000.

LE BRETON, David. A sociologia do corpo. Tradução de Sonia M.S Fuhrmann, Petrópolis: Vozes, 2006.

LEMEBEL, Pedro. La esquina es mi corazón. Santiago do Chile: Editorial Planeta Chilena, 2004.

LOPES, Denílson. O homem que amava rapazes e outros ensaios. Rio de Janeiro: Aeroplano, 2002.

LOYOLA, Maria Andréa. "A sexualidade como objeto de estudo nas ciências humanas". In: Sexualidade: o olhar das ciências sociais (org.) HEILBORN, Maria Luiza. Rio de Janeiro: Jorge Zahar Ed, 1999.

MALUF, Sônia Weidner. "Corpo e desejo: tudo sobre minha mãe e o gênero nas margens". Trabalho apresentado na Mesa Redonda Corpo, cultura e textualidade, no Seminário Internacional Fazendo Gênero 4, Florianópolis, UFSC, 2002.

------ "O dilema de Cênis e Tirésias: corpo, pessoa e as metamorfoses de gênero". In: LAGO, M., LEITE DA SILVA, A., RAMOS, T. Falas de Gênero. Florianópolis: Ed. Mulheres, 1999.

MOTTA, Flávia de Mattos. Velha é a vovozinha: identidade feminina na velhice. Santa Cruz do Sul: EDUNISC, 1998.

NANDA, Serena. "Hijars: An Alternative Sex and Gender Role in India". In: Gilbert Herdt (org). Third Sex, Third gender: Beyond Sexual Dimorphism in Culture and History. New York: Zone Brooks, 1994.

OLIVEIRA, Marcelo Dias de. O lugar do travesti em desterro. Dissertação de Mestrado apresentada ao programa de Pós-Graduação em Antropologia Social da Universidade Federal de Santa Catarina/PPGAS/UFSC, 1997.

PARKER, Richard. Abaixo do Equador. Culturas do desejo, homossexualidade masculina e comunidade gay no Brasil. Rio de Janeiro: Record, 2002. 
PEIXOTO, Clarice."Histórias de mulheres, de envelhecimento e de sexualidade". In: Guita Grin; GOLDSTEIN, Donna (orgs.). Políticas do corpo e curso da vida. São Paulo: Sumaré, 2000a.

----- Envelhecimento e imagem: as fronteiras entre Paris e Rio de Janeiro. São Paulo: Annablume, 2000b.

PERLONGER, Nestor. O negócio do michê: Prostituição viril em São Paulo. São Paulo: Brasiliense, 1987.

POLLACK, Michel. Memória, esquecimento e silencio. Estudos Históricos. 2 (3).Rio de Janeiro, v.2 n.3, 1989 .

SANTANA, Marco Aurélio. "Memória, cidade e cidadania” In: Memória e Espaço. Rio de Janeiro: 7 letras, 2000

SANTOS DE LIMA COSTA, Jorge Ricardo; BRITTO LEMOS, Maria Tereza Toríbio. "Lapa: desejos e subversões no espaço da cidade". In: BRITTO LEMOS, Maria Tereza Toribio; DE MORAES, Alves Nilson (orgs) Memória, Identidades e Representações. Rio de Janeiro: 7 letras, 2000

SILVA, Hélio R. S. Travesti: a invenção do feminino. Rio de Janeiro: Relume-Dumará; Iser, 1993.

---- "A sociedade dos travestis: espelhos, papéis e interpretações”. In: Sexualidades brasileiras. Rio de Janeiro: Relume-Dumará, 1996a.

---- Certas Cariocas: travestis e vida de rua no Rio de Janeiro. Rio de Janeiro: RelumeDumará, 1996b.

SILVA, Rogério Araújo da. Prostituição: artes e manhas do ofício. Goiânia: Cânone Editorial, Ed. UCG, 2006..

SIMMEL, Georg. "A Metrópole e a vida mental". In: VELHO, O.G .O fenômeno urbano. Rio de Janeiro:Zahar, 1967.

----- Sobre la individualidad y las formas sociales- 1 Ed. Quilmes, Universidade Nacional de Quilmes, 2002.

TELES DOS SANTOS, Jocélio. "Incorrigíveis, afeminados, desenfreados: indumentária e travestismo na Bahia do século XIX”. In: Revista de Antropologia. v. 40, nº. 2, 1997.

VELHO, Gilberto. 1999. Individualismo e cultura: notas para uma antropologia da sociedade contemporânea. Rio de Janeiro: Zahar, 1999.

--- Projeto e metamorfose: antropologia das sociedades complexas. Rio de Janeiro: Zahar, 1999

---- A Utopia Urbana. Rio de Janeiro: Zahar, 1993.

WELZER-LANG, Daniel." Os homens e o masculino numa perspectiva de relações sociais de sexo". In: RAISSA SCHPUN, Monica (org). Masculinidades. São Paulo: Boitempo Editorial: Santa Cruz do Sul, Edunisc, 2004. 